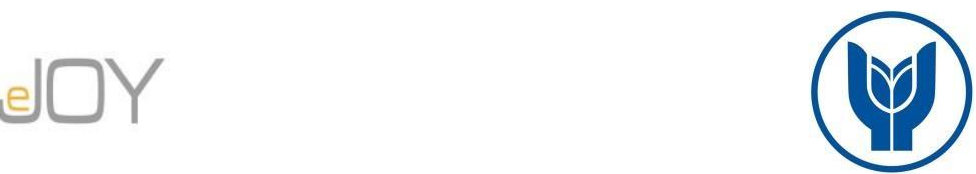

Kaya, F., Uğurhan, Y., Z., C., Bayçu Uzoğlu, S. / Journal of Yasar University, 2019, 14/54, 196-207

\title{
SOSYAL MEDYADA KISŞISEL MARKALAMA: NUSR-ET INSTAGRAM ÖRNEĞİ
}

\section{PERSONAL BRANDING IN SOCIAL MEDIA: NUSRET INSTAGRAM EXAMPLE}

\author{
Feyyaz KAYA, Türkiye, feyyazkaya@gmail.com \\ Yusuf Zafer Can UĞURHAN, Anadolu Üniversitesi, Türkiye, yzc_ugurhan@anadolu.edu.tr \\ Sevil UZOĞLU BAYÇU, Anadolu Üniversitesi, Türkiye, suzoglu@anadolu.edu.tr
}

\begin{abstract}
Öz: Kişisel markalama, günümüzde gittikçe önem kazanan bir kavram haline gelirken, kişisel markaların yaratılmasında, geliştirilmesinde ve büyütülmesinde sosyal ağlar da çok kullanışlı ve uygun maliyetli bir platform olarak karșımıza çıkmaktadır. Bu nedenle sosyal ağlara bağl bir topluma nasıl aktif bir katılım sağlanacağının anlaşılması önemlidir. Bu çalışma, sosyal ă̆ların kişisel markalama kavramı bağlamında nasıl kullanıldığını incelemektedir. Sosyal ağları kullanan kişisel markaların, çevrimiçi çalıșmalarında yeni kariyer firsatları, ortaklıkları ve takipçileriyle bașarıların nasıl arttırdığını analiz etmekte ve ayrıca sosyal medyanın güçlü bir kişisel markanın inşasında nasıl kullanılabileceğini göstermektedir. Bu kapsamda Nusr-et resmi Instagram hesabı kişisel markalama kavramı bağlamında içerik analizi yöntemi kullanılarak incelenmişstir.
\end{abstract}

Anahtar kelimeler: Kişisel Markalama, Kişisel Pazarlama, Sosyal Medya, Instagram

Abstract: While personal branding is becoming an increasingly important concept today, social networks have also been emerging as a very useful and cost effective platform to create, enhance and enlarge personal brands. Therefore, it is important to understand how to actively participate in a society based on social networks. This study examines how social networks are used in the context of personal branding. In this context, it was analyzed how personal brands using social networks have improved their success with new career opportunities, partnerships and followers in their online work, and it was demonstrated how social media can be used to build a strong personal brand. Within this scope, Nusr-et official Instagram account was examined using content analysis method in the context of personal branding concept.

\section{Giriș}

\section{Keywords: Personal Branding, Personal Marketing, Social Media, Instagram.}

Kişisel markalama, ürün ve şirketler için geliştirilen pazarlama ve markalaşma ilkelerini aynı şekilde bireylere uygulamanın mantığına dayanmaktadır (Schwabel 2009). İnsanlar bir marka olarak kabul edilebildiği gibi herkesin kişisel bir markası da olabilir. Kişisel markalama, bireyin kendisini bir marka olarak gördüğü ve iletişim kurduğu bir pazarlama iletişiminden oluşmaktadır. Sosyal medya, insanları yeni iş teknolojileri ile tanıştırırken kendilerini geliştirme imkânı sunmaktadır (Khedher, 2014, s.31 ve Peters, 1997, s.83). Markalama dünyasına giren bireyler için, kişisel marka, iş kariyerleri boyunca gerçekleștirdikleri faaliyetler ve mevcut iş teknolojilerinden oluşmaktadır. Bu yüzden başarılı bir iş kariyeri için tüm bu araçları anlamaları ve kullanmaları önemlidir.

Aslında, kişisel markalama, işletmeler, politika ve eğlence endüstrisindeki artan sayıda liderler ya da ünlüler vasıtasıyla ön plana çıkmıştır (Shepherd, 2005, s.590). Teknolojik gelişmeler internetin gelişmesini hızlandırırken, tüketiciler sosyal medya tarafından daha fazla güçlenmeye başlamıștır. Sosyal ağlar, kişisel bir markanın mesajlarını tüketicilerine iletmesine yardımcı olurken tüketicilerle doğrudan iletişim kurmaya ve onlarla etkileşim kurmaya yardımcı olmaktadır. Bilinirliği yüksek bir kişisel marka oluşturmak için sosyal ağ etkileşimi kritik bir bileşen olarak tanımlanmaktadır (Voorveld, vd., 2013, s.609). Bu çalışmada Instagram özelinde Nusr-et markasının yaptığı paylașımlarda bu platformu nasıl kullandığını, Nusr-et markasına ait ürün ve hizmet tanıtımlarının nasıl yapıldığını, bu içeriklere ait yorum, beğeni ve izlenme sayılarının nasıl dağılım gösterdiğini incelemek istenmiştir. Kişisel markalama sürecinde sosyal medyanın nasıl kullanıldığı tanımlanmaya çalışılmıştır.

\section{Kişisel Markalama}

İlk olarak Tom Peters (1997) tarafindan yazılan “The Brand Called You” adlı makalede popüler hale gelen kişisel markalama kavramı, dijital çağda giderek daha önemli bir konuma gelmiștir. Bir zamanlar yalnızca ünlüler ile iş ve siyaset liderleri için teknik bir araç olarak görülen kişisel markalama, internet ve yeni iletişim teknolojilerinin gelişmesiyle birlikte çerçevesini genişletmiş, çevrimiçi uygulamalar aracılığıyla sıradan insanlar için bile önemli bir pazarlama aracı olma özelliği kazanmıştır (Shepherd, 2005, s.589).

Tanım olarak kişisel markalama (KM), herkesin kendi markasına sahip olması ve kendi markası olan bir kişinin de temel ișinin kendi pazarlamacısı olması gerektiği olarak düşünülebilir. Çünkü kișisel markalamada insanlar kendi markalarının pazarlamacıları ve kendi şirketlerinin CEO’larıdır (Peters, 1997, s.83). Ürün markalama ile benzer şekilde kişisel markalama da bir kişinin hedef kitlesine güçlü yönlerini göstermeyi, kendi benzersizliğini yansıtmayı ve kendiyle 
bütünleştirdiği markaya onları teşvik etmeyi gerektirir (Kaputa, 2005 ve Shepherd, 2005, s.589). İş ortaklığı olarak olumlu bir profil oluşturmanın yanında beklentileri, hedefleri ve değerleri karşı tarafa iletebilmesi bakımından ayrıca stratejik bir pazarlama konseptidir (Ollington vd., 2013, s.258). Kişinin kendisi hakkında bir ürün olarak iletişim kurduğu bütünleşik pazarlama iletişimden oluşan kişisel markalamada insanlar marka olarak kabul edilir ve herkesin kişisel bir markası vardır (Khedher, 2014, s.31 ve Peters, 1997, s. 84).

KM' da bir markanın kendine özgü bir kimliğe ve benzersiz bir kişiliğe sahip olduğu öne sürülmüştür. KM sürecinin ürün markalaşmasını ya da kurumsal markalaşma sürecini yansıttığı ve üç aşamayı takip ettiği de belirtilmiştir (Arruda, 2003). Bu aşamalar kişisel bir markayı çıkarmak, onu hedef kitleye açıklamak ve yayarak markayı teşvik etmektir. Bu bağlamda öncelikle kişiler kendi belirleyici niteliklerini kendi içlerine bakarak keşfederler. Sonra bu özelliklerin etrafinda ilgi çekici bir kişisel marka ifadesi oluştururlar. Son olarak markayı dış dünyaya görünür kılmak için bir strateji oluştururlar.

Kişiler, sosyal medya kanallarını kullanarak hem kendi markalarını geliştirebilirler hem de hedef kitlelerine ulaşabilirler (Lair vd., 2005, s. 313). Bu kapsamda sosyal medya, bireyler için KM' da oldukça önemli bir alan konumundadır. Çünkü bireyler, kişisel performanslarını buradaki kanallar üzerinden göstererek onları rakiplerinden ayırmaya yardımcı olabilecek bireysellik hissini hedef kitlelerine sunarlar. Böylelikle her kişisel markanın kendine özgü bir kişiliği ve eşsizliği olduğu için temel karakter duygusunu yansıtırlar.

\section{Kişisel Markalamada Sosyal Medya Kullanımı}

Sosyal medya aracılığıyla, internet erişimi olan herhangi bir kişi düşüncelerini, fikirlerini, resimlerini ve videolarını çevrimiçi olarak milyonlarca insan ile paylaşabilme ve onlarla etkileşim kurabilme olanağına sahip olmuştur. Sosyal medyada etkileșimin temel amaçlarından biri yeni kişisel ilişkiler veya iş ilişskileri yaratmasıdır (Bădău, 2011).

Instagram, Twitter, Facebook gibi sosyal medya siteleri dünya çapında milyonlarca kullanıcıya ulaşan sanal topluluklara dönüşmüş durumdadır. Kullanıcıların büyük bir kısmının bu sitelerin kullanımını günlük rutinlerinin bir parçası haline getirmeleri, sosyal ă̆ sitelerinin öneminin gün geçtikçe artmasına neden olmaktadır (Dunne vd., 2010, s.48). Sosyal medya uygulamaları, iş yaklaşımını ve tüketicilerin etkileşim biçimini değiştiren etkili bir araç olarak kabul edilmektedir. İşletmelerin iş süreçlerini basitleştirmelerine, iç ve diş iletişimlerini oluşturmaya, işletme giderlerini azaltmaya, üretkenliği artırmaya ve müşterilerle her zamankinden daha etkin bir şekilde güçlü ilişkiler kurmasına olanak tanımaktadır (Kim vd., 2011, s.258). İnternet uygulamalarının da kapsamının giderek gelişmesi günümüzde şirketler üzerinde, internet ile ilgili teknolojilerin benimsenmesinde ve geliştirilmesinde bir etkiye sahip olmuştur. (Gubbi vd., 2013, s.1649).

Kişisel markalama yapılırken, sosyal medyanın kullanılması iyi bir seçenektir (Carlsson 2011). Markalar, sosyal medya aracılığıyla iletişim kurarak iletişim için daha fazla platform yaratırken uzun vadeli ilişkiler kurmak için bir araç, paydaşlar ile daha yakın bir bağlantı ve diyalog, mesajlarını yaymak için daha hızlı bir yol ve rekabeti analiz etmek için iyi bir ortam oluşturmaktadır (Carlsson, 2011).

Sosyal medyada marka iletişimi, markanın ve çalışanlarının, tüketicilerinin, gazetecilerin ve diğer paydaşların yarattığ 1 iletişimin bir parçasıdır. Bu nedenle bir marka, sosyal medyadaki tüm bilgileri kendi başına kontrol edemez (Carlsson, 2011). Sosyal medya, markalara daha fazla kişiselleştirme olanağı sağlarken tüketicileriyle güven, marka sadakati ve anlayış geliștirmeye yönelik bir şans vermektedir. (CIPR, 2012).

Instagram başta olmak üzere fotoğraf paylaşım sosyal ağları, tüketicilerin hedeflendiği, rekabet avantajı yüksek olan düşük maliyetli ve kaliteli bir ortamda kendilerini pazarlamak için iyi bir yoldur (Safko, 2012). Fotoğraf ve video paylaşımına dayanan Instagram'ın popülerliği giderek artmaktadır. Bu bağlamda Instagram'ı bir satış promosyon aracı olarak değil, markanın perde arkasındaki bilinirliğini gösterme firsatı sunan bir araç olarak öne çıkarmaktadır (Chan, 2011).

Instagram, internet kullanıcılarının günlük olarak kullandığı birçok sosyal medya uygulamasından biridir. Kevin Systrom ve Mike Krieger tarafından oluşturulan, 6 Ekim 2010 tarihinde piyasaya sürülen fotoğraf ve video paylaşım uygulamasıdır. Instagram'ın web sitesinde bulunan tanıma göre uygulama bir dizi fotoğrafla hayatınızı arkadaşlarınızla paylaşmanın eğlenceli ve ilginç bir yolu olarak tanımlanmaktadır (Instagram, 2018). Uygulama, bir fotoğraf çekmek için cep telefonunu kullanmasına, görüntüyü dönüştürmek için bir filltre seçmesine ve uygulamada yayınlamasına izin vermektedir. Her kullanıcı profilinde, kaç kişiyi takip ettiklerini ve bunları kaç kullanıcının izlediğini gösteren bir “Takipçiler" ve "Takip" sayısı bulunmaktadır (Webtrends, 2015). Diğer kişilerle etkileşimde bulunmak için paylaşımın üzerindeki beğeni ya da yorum düğmesine dokunarak içeriğe beğeni veya yorum yapılmaktadır. Uygulama gelişmeye devam ettikçe bünyesine daha fazla özellik eklemiştir. Instagram, Ocak 2011'de, hem fotoğrafları hem de birbirlerini keşfetmesine yardımcı olmak için hashtag kullanımını kullanıcılarına sunmuştur. Bir hashtag, (\#) işareti ile belirtilen ve belirli bir konudaki mesajları tanımlamak için kullanılan bir kelime veya ifade olarak tanımlanabilir. Aralık 2013'te ise Instagram Direkt Mesaj özelliği eklenmiştir. Bu özellik, kullanıcıların belirli kişilerden doğrudan mesajlaşmasına izin vermektedir. Son yıllarda Instagram, insanların birbirleriyle görsel olarak da paylaşabileceği ve etkileşimde bulunabileceği bir yer haline gelmiştir.

Sosyal medya pazarlaması, sosyal ağ sitelerinin pazarlama aracı olarak kullanılmasıdır (Rouse, 2011). Markalar için en yeni pazarlama ve reklam biçimi haline gelmiştir. Rouse (2011), sosyal medya pazarlamasının amacının, bir markanın 
tüketici etkileşimini artırmalarına yardımcı olmak için sosyal ağlarda içerik üretmek olduğunu belirtmektedir. Bu tür pazarlama, sosyal ağ trafiğini tanıtmak ve kullanıcılarla etkileşimde bulunmak için Facebook, Twitter, Instagram gibi çeşitli sosyal ağ siteleri aracılığıyla gerçekleştirilmektedir. Başarılı bir sosyal medya pazarlaması, belli bir hedef kitleyi çeken ve markanın yarattığı içeriklerin sosyal medya kullanıcıları tarafindan paylaşımları yapıldığı zaman anlaşılmaktadır.

\section{Yöntem}

Bu çalışmanın amacı, Nusr-et markası tarafından Instagram üzerinden yapılan paylaşımlarda bu platformu nasıl kullandığını, Nusr-et markasına ait ürün ve hizmet tanıtımlarının nasıl yapıldığını ve bu içeriklere ait yorum, beğeni ve izlenme sayılarının nasıl dağılım gösterdiğini incelemektir. Ayrıca Nusr-et Instagram hesabındaki ünlü kullanımının olduğu paylaşımların takipçi sayısı artışıyla bir ilişkisinin olup olmadığı incelenmek istenmiş ve Ki-Kare (Chi-Square) test ile analiz edilmiştir. Bu kapsamda aşağıdaki araştırma soruları cevaplandırılmak istenmiştir:

1. Nusr-et Instagram hesabında paylaşımların temalara göre dağılımı nasıldır?

2. Nus-et Instagram hesabında temalara göre takipçi sayısı, gönderi sayısı, beğeni sayısı ve yorum sayısı dağılımları nasildir?

3. Nusr-et Instagram hesabında ünlü kullanımı olan paylaşımların takipçi sayısı arasında bir ilişki var mıdır?

Nusr-et Instagram hesabında incelemeler 01.01.2017 ve 01.03.2018 tarihleri arasından olmak üzere on dört aylık süreç üzerinden yapılmıştır. Çalışmada bu tarihler belirlenirken toplam takipçi sayısının 2017 yılı 1 Ocak ayı itibarı ile 961.864 iken, 2018 Mart 1 Mart ayı itibarı ile 11.692.690 olması göz önünde bulundurulmuştur (Boomsocial, 2018). Bu artışta içeriklerin nasıl dağılım gösterdiği ve hangi içerik temalarının daha çok ön plana çıktığını bulmak amaçlanmıştır. Ayrıca içerik temalarıyla, betimleyici araştırma desenine yer verirken, veriler içerik analizi yöntemi ile elde edilmiştir. Nusr-et Instagram hesabındaki her bir paylaşım, çalışmanın analiz birimini oluşturmaktadır.

İçerik analizi, araştırma evrenini kapsayan verilerden belirlenen ve bütünü yansıtan örneklemin incelenmesi ve içeriğin önceden belirlenen kategorilere göre sınıflandırılması olarak ifade edilmektedir (Wimmer ve Dominick, 2007, s.19). İçerik analizinde amaç, toplanan verilerin açıklanmasını sağlayabilecek kavram ve ilişkileri ortaya koymaktır. Betimsel analizde özetlenen veriler, içerik analizinde daha derin işlemlere tabi tutulmaktadır. Bu nedenle elde edilen verilerin önce kavramsallaştırılması, sonra elde edilen verilen düzenlenmesi ve açıklayıcı temaların oluşması gerekmektedir (Yıldırım ve Şimşek, 2016, s.259). İçerik analizi, genelde sayıları fazla olan görsel veya metin içeriklerinin ortak yönlerini ortaya koyarken, araştırma sürecinde ise her bir aşamayı birbirinden ayırmaktadır (Gökçe, 2006, s.18).

Çalışmada iki kodlayıcıdan yararlanılmıştır. Kodlayıcılar arası tutarlılık olup olmadığını belirlemek amacıyla Kappa analizi yapılmış ve kodlayıcılar arası tutarlılık 0.86 olarak tespit edilmiştir. İki kodlayıcı aynı verileri kodladığında ölçümler arasında güvenilirliği kontrol etmek için genellikle Cohen’s Kappa hesaplanmaktadır. Cohen’s Kappa, kategorik değişkenler üzerinde kodlayıcılar arası tutarlılı̆̆ı hesaplamak için kullanılır ve 0 ile 1 arasında değer alır. Ancak iyi bir tutarlılık için Cohen's Kappa katsayısının en az 0.70 ve üzerinde bir değer alması gerekir. (Leech, Barrett ve Morgan, 2008, s.54-56). Bu çalışmada ise elde edilen Cohen's Kappa katsayısının 0.86 olması kodlayıcılar arasında iyi bir tutarlılık olduğunu göstermektedir.

\section{Bulgular}

Çalışma kapsamında incelenen Nusr-et markasının resmi Instagram sayfasında 01.01.2017 ve 01.03.2018 tarihleri arasında paylaşılan içeriklere yönelik bilgiler Tablo 1'de sunulmaktadır. Bu tarihler arasında toplamda 209 tane içerik paylaşılmıştır. İçerikler, fotoğraf ve video şeklinde olmak üzere iki farklı türde ele alınmıştır. Bununla birlikte çalışmada incelenen içeriklerin teması 6 kategoriye ayrılmıştır. Bunlar sosyal hayat, ünlü kullanımı, ürün ve hizmetler, iş yerinin, ürün ve hizmetlerin ya da marka görselinin beraber kullanımı, başka kişi ya da kurumun tanıtımı ve diğger paylaşımlar kategorisinden oluşmaktadır.

Tablo 1. Instagram Paylaşımlarına İlişkin Betimsel Bulgular

\begin{tabular}{|c|c|c|c|c|c|}
\hline \multicolumn{3}{|c|}{ Paylaşım Türü } & \multicolumn{3}{|c|}{ Paylaşımlardaki Marka Görseli } \\
\hline & $N$ & $\%$ & & $n$ & $\%$ \\
\hline Fotoğraf & 78 & 37,3 & Kullanılmamış & 115 & 55 \\
\hline Video & 131 & 62,7 & Logo & 6 & 2,9 \\
\hline \multirow{2}{*}{ Toplam } & \multirow{2}{*}{209} & \multirow{2}{*}{100} & Tuzlama Hareketi & 88 & 42,1 \\
\hline & & & Toplam & 209 & 100 \\
\hline \multicolumn{3}{|c|}{ Paylaşımların Temaları } & \multicolumn{3}{|c|}{ Paylaşımlarda Ürün ya da Hizmet Tanıtımı* } \\
\hline & $N$ & $\%$ & & $n$ & $\%$ \\
\hline Sosyal hayat & 40 & 19,1 & Var & 137 & 65,6 \\
\hline Ünlü kullanımı & 45 & 21,5 & Yok & 72 & 34,4 \\
\hline
\end{tabular}


Kaya, F., Uğurhan, Y., Z., C., Bayçu Uzoğlu, S. / Journal of Yasar University, 2019, 14/54, 196-207

\begin{tabular}{|c|c|c|c|c|c|}
\hline Ürün ve Hizmetler & 33 & 15,8 & Toplam & 209 & 100 \\
\hline $\begin{array}{l}\text { İş yerinin, ürün ve hizmetlerin } \\
\text { da marka görselinin beraber }\end{array}$ & \multirow{2}{*}{55} & \multirow{2}{*}{26,3} & \multicolumn{3}{|c|}{ Paylaşımlarda Başka Kişi ya da Kurum Tanıtım } \\
\hline kullanımı & & & & $n$ & $\%$ \\
\hline Başka kişi ya da kurumun tanı & 4 & 1,9 & Var & 3 & 1,4 \\
\hline Diğer paylaşımlar & 32 & 15,3 & Yok & 206 & 98,6 \\
\hline Toplam & 209 & 100 & Toplam & 209 & 100 \\
\hline \multicolumn{6}{|c|}{ Paylaşımlarda Ünlü Kullanımı } \\
\hline & & & $N$ & \multicolumn{2}{|c|}{$\%$} \\
\hline \multicolumn{2}{|l|}{ Doğrudan var } & & 24 & \multicolumn{2}{|c|}{11,5} \\
\hline \multicolumn{2}{|l|}{ Dolaylı var } & & 20 & \multicolumn{2}{|c|}{9,6} \\
\hline \multicolumn{2}{|l|}{ Yok } & & 165 & \multicolumn{2}{|c|}{78,9} \\
\hline \multicolumn{2}{|l|}{ Toplam } & & 209 & \multicolumn{2}{|c|}{100} \\
\hline
\end{tabular}

*: Farklı bir kategori içinde ürün ya da hizmet tanıtımı; *: Farklı bir kategori içinde başka kişi ya da kurum tanıtımı.

Nusr-et markasının Instagram hesabındaki paylaşımlarda paylaşım türü bağlamında daha çok video paylaşımlar yer alırken $(\% 62,7)$, fotoğraf paylaşımları daha az $(\% 37,3)$ yer almaktadır. Paylaşımlarda marka görseli kullanımı daha çok tuzlama hareketi $(\% 42,1)$ aracılığıyla yapılmaktayken, marka logosu ise daha az $(\% 2,9)$ kullanılmaktadır. Paylaşım temasında en çok "iş yerinin, ürün ve hizmetlerin ya da marka görselinin beraber kullanımı" kategorisi bulunurken (\%26,3), en az "başka kişi ya da kurumun tanıtımı” kategorisi $(\% 1,9)$ bulunmaktadır. Paylaşımlarda "ürün ya da hizmet tanıtımı" ağırlıklı olarak yapılırken $(\% 65,6)$, "başka kişi ya da kurum tanıtımı” ise daha az $(\% 1,4)$ yapılmaktadır. Ünlü kullanımının olduğu paylaşımlar daha çok doğrudan yapılırken $(\% 11,5)$, ünlü kullanımının dolaylı olduğu paylaşımlar nispeten daha az $(\% 9,6)$ kullanılmaktadır.

Tablo 2. Paylaşım Teması Ve Paylaşım Türüne Göre Yapılan Çapraz Tablolama

\begin{tabular}{|c|c|c|c|}
\hline \multirow{2}{*}{ Paylaşım Teması } & \multicolumn{2}{|c|}{ Paylaşım Türü } & \multirow{2}{*}{ Toplan } \\
\hline & Fotoğra & Video & \\
\hline \multirow{2}{*}{ Sosyal hayat } & 18 & 22 & 40 \\
\hline & $\% 8,6$ & $\% 10,5$ & $\% 19,1$ \\
\hline \multirow{2}{*}{ Ünlü kullanımı } & 23 & 22 & 45 \\
\hline & $\% 11$ & $\% 10,5$ & $\% 21,5$ \\
\hline \multirow{2}{*}{ Ürün ve hizmetler } & 9 & 24 & 33 \\
\hline & $\% 4,3$ & $\% 11,5$ & $\% 15,8$ \\
\hline \multirow{2}{*}{ İş yerinin, ürün ve hizmetlerin veya marka görselinin birlikte kullan } & 4 & 51 & 55 \\
\hline & $\% 1,9$ & $\% 24,4$ & $\% 26,3$ \\
\hline \multirow{2}{*}{ Başka kişi ya da kurumun tanıtımı } & 0 & 4 & 4 \\
\hline & $\% 0$ & $\% 1,9$ & $\% 1,9$ \\
\hline \multirow{2}{*}{ Diğer } & 24 & 8 & 32 \\
\hline & $\% 11,5$ & $\% 3,8$ & $\% 15,3$ \\
\hline \multirow{2}{*}{ Toplam } & 82 & 127 & 209 \\
\hline & $\% 37,3$ & $\% 62,7$ & $\% 100$ \\
\hline
\end{tabular}

Paylaşım temasındaki kategorilerde video paylaşımlar daha çok kullanılırken $(\% 62,7)$, fotoğraf paylaşımları daha az $(\% 37,3)$ kullanılmaktadır. Fotoğraf paylaşımlarında en çok “diğer paylaşımlar” kategorisi bulunurken (\%11,5), "başka kişi ya da kurumun tanıtımı" kategorisi hiç yer (\%0) almamaktadır. Video paylaşımı biçiminde en fazla "iş yerinin, ürün ve hizmetlerin veya marka görselinin birlikte kullanımı” kategorisi bulunurken (\%24,4), en az "başka kişi ya da kurumun tanıtımı" kategorisi $(\% 1,9)$ yer almaktadır. 
Kaya, F., Uğurhan, Y., Z., C., Bayçu Uzoğlu, S. / Journal of Yasar University, 2019, 14/54, 196-207

Tablo 3. Paylaşım Teması Ve Paylaşımların Beğeni Sayısına İlişkin Yapılan Çapraz Tablolama

\begin{tabular}{|c|c|c|c|c|c|}
\hline \multirow[b]{2}{*}{ Paylaşım Teması } & \multicolumn{4}{|c|}{ Beğeni Sayısı } & \multirow[b]{2}{*}{ Toplan } \\
\hline & 100,000 ve & $\begin{array}{r}100,001 \\
500,000 \text { al }\end{array}$ & $\begin{array}{r}500,001 \\
1,000,000\end{array}$ & $1,000,001$ ve & \\
\hline \multirow[t]{2}{*}{ Sosyal hayat } & 1 & 24 & 13 & 2 & 40 \\
\hline & $\% 5$ & $\% 11,5$ & $\% 6,2$ & $\% 1$ & $\% 19,1$ \\
\hline \multirow{2}{*}{ Ünlü kullanımı } & 0 & 28 & 15 & 2 & 45 \\
\hline & $\% 0$ & $\% 13,4$ & $\% 7,2$ & $\% 1$ & $\% 33$ \\
\hline \multirow{2}{*}{ Ürün ve hizmetler } & 0 & 14 & 18 & 1 & 33 \\
\hline & $\% 0$ & $\% 6,7$ & $\% 8,6$ & $\% 0,5$ & $\% 15,8$ \\
\hline \multirow{2}{*}{$\begin{array}{c}\text { İş yerinin, ürün ve hizmetlerin veya mə } \\
\text { görselinin birlikte kullanımı }\end{array}$} & 0 & 17 & 36 & 2 & 55 \\
\hline & $\% 0$ & $\% 8,1$ & $\% 17,2$ & $\% 1$ & $\% 26,3$ \\
\hline \multirow{2}{*}{ Başka kişi ya da kurumun tanıtımı } & 1 & 3 & 0 & 0 & 4 \\
\hline & $\% 0,5$ & $\% 1,4$ & $\% 0$ & $\% 0$ & $\% 1,9$ \\
\hline \multirow{2}{*}{ Diğer } & 1 & 15 & 15 & 1 & 32 \\
\hline & $\% 0,5$ & $\% 7,2$ & $\% 7,2$ & $\% 0,5$ & $\% 15,3$ \\
\hline \multirow{2}{*}{ Toplam } & 3 & 101 & 97 & 8 & 209 \\
\hline & $\% 1,4$ & $\% 48,3$ & $\% 46,4$ & $\% 3,8$ & $\% 100$ \\
\hline
\end{tabular}

Paylaşım temasındaki kategorilerde "100,000 ve altı” beğeni sayısına sahip üç temanın toplamda üç paylaşımı $(\% 1,4)$ bulunmaktadır. “100,001 ve 500,000” beğeni sayısına sahip altı kategorinin toplamda 101 paylaşımı $(\% 48,3)$ varken " 500,001 ve 1,000,000 arası" beğeni sayısına sahip beş temanın toplamda 97 paylaşımı (\%46,4) bulunmaktadır. "1,000,001 ve üstü” beğeni sayısına sahip beş kategorinin toplamda sekiz paylaşımı $(\% 3,8)$ vardır. En çok paylaşım sayısı olan "iş yerinin, ürün ve hizmetlerin veya marka görselinin birlikte kullanımı" kategorisinin 100,001 ve 1,000,000 aralığında beğeni sayısına sahip 53 paylaşıma (\%25,3) sahipken en az paylaşım sayısına sahip "başka kişi ya da kurumun tanıtımı" kategorisinin 500,001 ve üstünde beğeni sayısı alan hiçbir paylaşımı bulunmamaktadır. Ayrıca ünlü kullanımının olduğu paylaşımlar daha çok 100,001 ve 500,000 aralığında $(\% 13,4)$ beğeni sayısı almıştır.

Tablo 4. Paylaşım Teması Ve Paylaşımların Yorum Sayısına İlişkin Yapılan Çapraz Tablolama

\begin{tabular}{|c|c|c|c|c|c|}
\hline \multirow{2}{*}{ Paylaşım Teması } & \multicolumn{4}{|c|}{ Yorum Sayısı } & \multirow[b]{2}{*}{ Toplan } \\
\hline & 1 ve 5,000 : & $\begin{array}{r}5,001 \text { ve } 10 \\
\text { arası }\end{array}$ & $\begin{array}{r}10,001 \text { ve } 21 \\
\text { arası }\end{array}$ & 20,001 ve $i$ & \\
\hline \multirow{2}{*}{ Sosyal hayat } & 24 & 11 & 4 & 1 & 40 \\
\hline & $\% 11,5$ & $\% 5,3$ & $\% 1,9$ & $\% 0,5$ & $\% 19,1$ \\
\hline \multirow{2}{*}{ Ünlü kullanımı } & 30 & 9 & 3 & 3 & 45 \\
\hline & $\% 14,4$ & $\% 4,3$ & $\% 1,4$ & $\% 1,4$ & $\% 21,5$ \\
\hline \multirow{2}{*}{ Ürün ve hizmetler } & 11 & 11 & 7 & 4 & 33 \\
\hline & $\% 5,3$ & $\% 5,3$ & $\% 3,3$ & $\% 1,9$ & $\% 15,8$ \\
\hline \multirow{2}{*}{$\begin{array}{c}\text { İş yerinin, ürün ve hizmetlerin veya ma } \\
\text { görselinin birlikte kullanımı }\end{array}$} & 10 & 13 & 21 & 11 & 55 \\
\hline & $\% 4,8$ & $\% 6,2$ & $\% 10$ & $\% 5,3$ & $\% 26,3$ \\
\hline \multirow{2}{*}{ Başka kişi ya da kurumun tanıtımı } & 3 & 1 & 0 & 0 & 4 \\
\hline & $\% 1,4$ & $\% 0,5$ & $\% 0$ & $\% 0$ & $\% 1,9$ \\
\hline \multirow{2}{*}{ Diğer } & 20 & 4 & 6 & 2 & 32 \\
\hline & $\% 9,6$ & $\% 1,9$ & $\% 2,9$ & $\% 1$ & $\% 15,3$ \\
\hline \multirow{2}{*}{ Toplam } & 98 & 49 & 41 & 21 & 209 \\
\hline & $\% 46,9$ & $\% 23,4$ & $\% 19,6$ & $\% 10$ & $\% 100$ \\
\hline
\end{tabular}

Paylaşım temasında "1 ve 5,000 arası" yorum sayısına sahip altı kategorinin toplamda 98 paylaşımı $(\% 46,9)$ bulunmaktadır. "5,001 ve 10,000" yorum sayısına sahip altı kategorinin toplamda 49 paylaşımı $(\% 23,4)$ varken " 10,001 ve 20,000" arası yorum sayısına sahip beş kategorinin toplamda 41 paylaşımı $(\% 19,6)$ bulunmaktadır. "20,001 ve üstü”" 
yorum sayısına sahip beş kategorinin toplamda 21 paylaşımı (\%10) vardır. En çok paylaşım sayısı olan "iş yerinin, ürün ve hizmetlerin veya marka görselinin birlikte kullanımı" kategorisi, 10,001 ve üstünde yorum sayısına sahip 32 paylaşıma $(\% 15,3)$ sahipken en az paylaşım sayısına sahip "başka kişi ya da kurumun tanıtımı" kategorisinin ise 10,001 ve üstünde yorum sayısına sahip hiç paylaşımı bulunmamaktadır. Ayrıca ünlü kullanımının olduğu paylaşımlar daha çok " 1 ve 5,000” arasında yorum sayısına sahiptir.

Tablo 5. Paylaşım Teması Ve Video Paylaşımların İzlenme Sayısına İlişkin Yapılan Çapraz Tablolama

\begin{tabular}{|c|c|c|c|c|c|}
\hline \multirow[b]{2}{*}{ Paylaşım Teması } & \multicolumn{4}{|c|}{ Video Paylaşımların İzlenme Sayısı } & \multirow[b]{2}{*}{ Toplan } \\
\hline & $\begin{array}{r}1,000,000 \\
5,000,000\end{array}$ & $\begin{array}{r}5,000,001 \\
10,000,000\end{array}$ & $\begin{array}{r}10,000,00 \\
15,000,000\end{array}$ & $\begin{array}{c}15,000,001 \\
\text { üstü }\end{array}$ & \\
\hline \multirow{2}{*}{ Sosyal hayat } & 9 & 11 & 2 & 0 & 22 \\
\hline & $\% 6,9$ & $\% 8,4$ & $\% 1,5$ & $\% 0$ & $\% 16,8$ \\
\hline \multirow{2}{*}{ Ünlü kullanımı } & 9 & 12 & 0 & 1 & 22 \\
\hline & $\% 6,9$ & $\% 9,2$ & $\% 0$ & $\% 0,8$ & $\% 16,8$ \\
\hline \multirow{2}{*}{ Ürün ve hizmetler } & 1 & 17 & 5 & 1 & 24 \\
\hline & $\% 0,8$ & $\% 13$ & $\% 3,8$ & $\% 0,8$ & $\% 18,3$ \\
\hline \multirow{2}{*}{$\begin{array}{c}\text { İş yerinin, ürün ve hizmetlerin veya ma } \\
\text { görselinin birlikte kullanımı }\end{array}$} & 5 & 23 & 20 & 3 & 51 \\
\hline & $\% 3,8$ & $\% 17,6$ & $\% 15,3$ & $\% 2,3$ & $\% 38,9$ \\
\hline \multirow{2}{*}{ Başka kişi ya da kurumun tanıtımı } & 3 & 1 & 0 & 0 & 4 \\
\hline & $\% 2,3$ & $\% 0,8$ & $\% 0$ & $\% 0$ & $\% 3,1$ \\
\hline \multirow{2}{*}{ Diğer } & 3 & 3 & 2 & 0 & 8 \\
\hline & $\% 2,3$ & $\% 2,3$ & $\% 1,5$ & $\% 0$ & $\% 6,1$ \\
\hline \multirow{2}{*}{ Toplam } & 30 & 67 & 29 & 5 & 131 \\
\hline & $\% 22,9$ & $\% 51,1$ & $\% 22,1$ & $\% 3,8$ & $\% 100$ \\
\hline
\end{tabular}

Paylaşım temasındaki kategorilerde bulunan video paylaşımlarda "1,000,000 ve 5,000,000 arası" izlenme sayısına sahip altı kategorinin toplamda 30 paylaşımı $(\% 22,9)$ bulunmaktadır. "5,000,001 ve 10,000,000 arası" izlenme sayısına sahip altı kategorinin toplamda 67 paylaşımı $(\% 51,1)$ varken "10,000,001 ve 15,000,000 arası" izlenme sayısına sahip dört kategorinin toplamda 29 paylaşımı $(\% 22,1)$ bulunmaktadır. "15,000,001 ve üstünde” izlenme sayısına sahip üç kategorinin toplamda 5 paylaşımı $(\% 3,8)$ vardır. En çok paylaşım sayısı olan "iş yerinin, ürün ve hizmetlerin veya marka görselinin birlikte kullanımı" kategorisi 5,000,001 ile 15,000,000 aralığında izlenme sayısına sahip 43 paylaşıma (\%32,9) sahipken en az paylaşım sayısına sahip "başka kişi ya da kurumun tanıtımı” kategorisinin ise 10,000,001'in üstünde izlenme sayısına sahip paylaşımı bulunmamaktadır. Ayrıca ünlü kullanımının olduğu video paylaşımlar, daha çok $1,000,000$ ile 10,000,000 aralı̆̆ında izlenme sayısına sahiptir. 
Tablo 6. Paylaşım Teması Ve Takipçi Sayısı Artışı

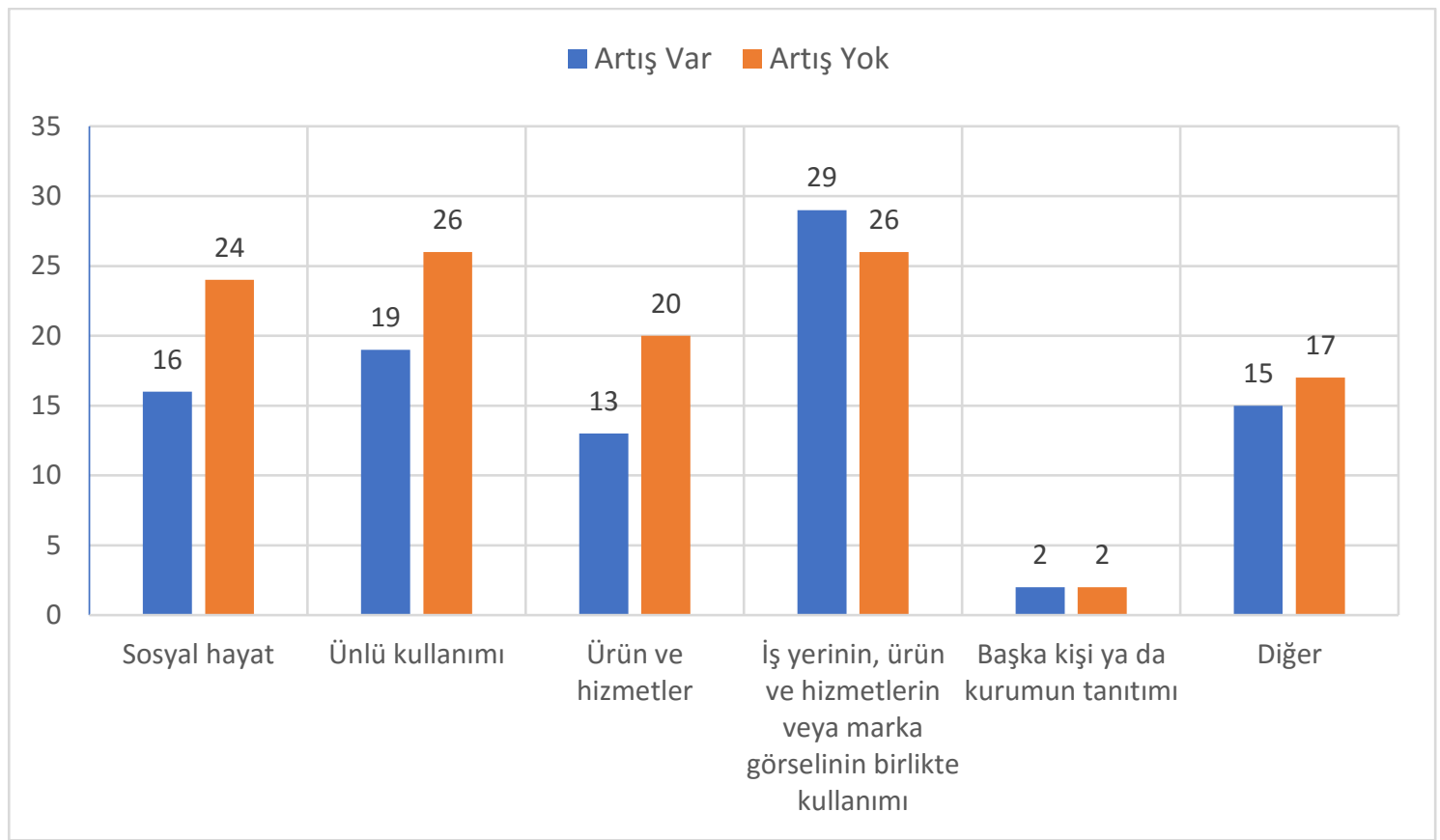

Paylaşım temasında paylaşıma göre takipçi sayısının bir önceki güne göre daha fazla artış gösterdiği tek kategori “iş yerinin, ürün ve hizmetlerin veya marka görselinin birlikte kullanımı" (n:55) kategorisidir. "Başka kişi ya da kurumun tanıtımı" kategorisindeki paylaşımlarda takipçi sayısının bir önceki güne göre daha fazla ya da daha az artış gösterdiği paylaşım sayıları eşit dağılım gösterirken (n:4) diğer dört kategorinin paylaşımlarında bir önceki güne göre daha az takipçi sayısı artışı olduğu görülmektedir.

Tablo 7. Paylaşımlarda Ünlü Kullanımı Ile Takipçi Sayısı Artış Durumu Arasındaki Ilişkiye Yönelik Ki-Kare (ChiSquare) Bağımsızlık Testi Sonucu

\begin{tabular}{|c|c|c|c|c|c|c|}
\hline \multirow[b]{2}{*}{ Ünlü Kullanı } & \multicolumn{3}{|c|}{ Takipçi Sayısı Artış Durumu } & \multirow[b]{2}{*}{$X^{2}$} & \multirow[b]{2}{*}{ df } & \multirow[b]{2}{*}{$p$} \\
\hline & $\begin{array}{c}\text { Bir Önceki Güne Göre A } \\
\text { Var }\end{array}$ & $\begin{array}{c}\text { Bir Önceki Güne Göre } \\
\text { Yok }\end{array}$ & Topla & & & \\
\hline \multirow{2}{*}{ Var } & 19 & 26 & 45 & \multirow{6}{*}{0,17} & \multirow{6}{*}{1} & \multirow{6}{*}{0,6} \\
\hline & $\% 9,1$ & $\% 12,4$ & $\% 21$, & & & \\
\hline \multirow{2}{*}{ Yok } & 75 & 89 & 164 & & & \\
\hline & $\% 35,9$ & $\% 42,6$ & $\% 78$ & & & \\
\hline \multirow{2}{*}{ Toplam } & 94 & 115 & 209 & & & \\
\hline & $\% 45$ & $\% 55$ & $\% 10$ & & & \\
\hline
\end{tabular}

Instagram paylaşımlarında ünlü kullanımı ile takipçi sayısı artış durumu arasında bir ilişki olup olmadığı tespit edebilmek amacıyla yapılan Ki-Kare Bağımsızlık Testi sonucuna göre ünlü kullanımı kategorisi ile takipçi sayısı artış arasında anlamlı bir ilişki bulunamamıştır ( $p>0,05)$. Tablo 7'ye göre Instagram paylaşımlarında ünlü kullanımının olduğu paylaşım sayısı 45 ve ünlü kullanımının olmadığ1 paylaşım sayısı ise 164'tür. Ünlü kullanımının olduğu ve takipçi sayısı artışı bağlamında bir önceki güne göre daha fazla artış sağlayan paylaşım sayısı 19, bir önceki güne göre daha fazla artış sağlamayan ünlü kullanımının olduğu paylaşım sayısı ise 26'dır. 
Tablo 8. Paylaşımlarda Iş Yerinin, Ürün Ve Hizmetlerin Ya Da Marka Görselinin Birlikte Kullanımı Ile Takipçi Sayısı Artış Durumu Arasındaki Ilişkiye Yönelik Ki-Kare (Chi-Square) Bağımsızlık Testi Sonucu

\begin{tabular}{|c|c|c|c|c|c|c|}
\hline \multirow{2}{*}{$\begin{array}{l}\text { İş yerinin, ürüı } \\
\text { hizmetlerin ya } \\
\text { marka görseli } \\
\text { birlikte kullan }\end{array}$} & \multicolumn{3}{|c|}{ Takipçi Sayısı Artış Durumu } & \multirow[b]{2}{*}{$X^{2}$} & \multirow[b]{2}{*}{ df } & \\
\hline & $\begin{array}{c}\text { Bir Önceki Güne Göre A } \\
\text { Var }\end{array}$ & $\begin{array}{c}\text { Bir Önceki Güne Göre t } \\
\text { Yok }\end{array}$ & Topla & & & $p$ \\
\hline \multirow{2}{*}{ Var } & 29 & 26 & 55 & \multirow{6}{*}{1,81} & \multirow{6}{*}{1} & \multirow{6}{*}{$0,1^{\prime}$} \\
\hline & $\% 13,9$ & $\% 12,4$ & $\% 26$, & & & \\
\hline \multirow{2}{*}{ Yok } & 65 & 89 & 154 & & & \\
\hline & $\% 31,1$ & $\% 42,6$ & $\% 73$ & & & \\
\hline \multirow{2}{*}{ Toplam } & 94 & 115 & 209 & & & \\
\hline & $\% 45$ & $\% 55$ & $\% 10$ & & & \\
\hline
\end{tabular}

Instagram paylaşımlarında iş yerinin, ürün ve hizmetlerin ya da marka görselinin beraber kullanımı ile takipçi sayısı artış durumu arasında bir ilişki olup olmadığı belirlemek amacıyla yapılan Ki-Kare Bağımsızlık Testi sonucuna göre iş yerinin, ürün ve hizmetlerin ya da marka görselinin beraber kullanımı kategorisi ile takipçi sayısı artış arasında anlamlı bir ilişki bulunamamıştır ( $p>0,05)$. Tablo 8'e göre Instagram paylaşımlarında iş yerinin, ürün ve hizmetlerin ya da marka görselinin beraber kullanımının olduğu paylaşım sayısı 55 ve ünlü kullanımının olmadığı paylaşım sayısı ise 154 'tür. İş yerinin, ürün ve hizmetlerin ya da marka görselinin beraber kullanımının olduğu ve takipçi sayısı artışında bir önceki güne göre daha fazla artış sağlayan paylaşım sayısı 29, bir önceki güne göre daha fazla artış sağlamayan paylaşım sayısı ise $26^{\prime}$ dir.

\section{Sonuç}

Herkesin kişisel bir markası olduğu söylenebilir, önemli olan onunla ne yapıldığı nasıl yapıldığıdır. Herhangi bir marka gibi kişisel marka da bilinçli bir şekilde yönetilmelidir. Kişisel markanın tanıtımında, sosyal medya platformları çok kullanışlı, kullanımı kolay ve maliyeti uygundur (Buckmann, 2017). Kişisel markalama sadece yapılan işin getirdiği ün değil, yapılan işle ortaya konulan farklılık ve geri bildirimler dikkate alınarak iyi bir şekilde tanıtılan marka ile ikna gücüdür.

Günümüzde sosyal ağlar, bir itibar oluşturmak ve belirli bir sektörde görünür hale gelmek ve kişisel kimlik oluşturmak için en iyi ve en kolay yoldur. Kişisel markanın hayata geçirilmesi için sosyal ağlar mükemmel bir yerdir çünkü insanlar artık çevrimiçi durumdadır. Bu sayede insanlar, markanın karakteri ve yaptıkları hakkında bilgi sahibi olmak istediklerinde bulacakları yerler vardır.

Sosyal medya uygulamalarının hem kapsamlarının hem de kullanımlarının genişlemesi şirketleri, maliyet tasarrufu ve marka sadakatini arttırmak gibi avantajları nedeniyle pazarlama iletişimi aracı olarak kendi çevrimiçi marka topluluklarını yaratma çalışmalarına sevk etmiştir (Choi ve DiNitto 2013). Bu kapsamda sosyal medya tüketici odaklı bilgi, bireysel farkındalık yaratmak, güven inşa etmek, bireysel seviyede farklılaşmayı sağlamak ve yeni bir işe dönüştürülebilecek kişisel markalamadaki beklentileri yönetmek için önemli bir araç haline gelmiştir (Vitberg, 2010, s.43). Kişisel markalamayı sosyal medya aracılığıyla gerçekleştirmek diğer mecraların ihtiyaç duyduğu kadar çaba harcamadan iletişim kurmak istenilen insanlara daha kolay ulaştırabilmektedir. Ayrıca, genellikle markalaşma çabaları için önemli miktarda mali destek gerektirse de, sosyal medya bir kişinin kendisini bir şekilde marka olarak tanıtması için uygun bir firsat sunmaktadır (Kaplan ve Haenlein, 2010, s.62).

Kişisel markalama, etkili bir pazarlama stratejisinin önemli bir bileşenidir. Markanın, karakterini, değerlerini, misyon ve vizyonunu çalışanlara ve müşterilere iletmeyi içerir. Günümüz iş dünyasında, markaları birbirinden ayırmak, sadık müşteri tabanı oluşturmak için çok önemlidir. Sosyal medya bunlar için firsatlar yaratabilir, kişisel markalar için kariyer kapılarını açabilir, büyüme ve gelişme için yeni firsatlar getirebilir. Sosyal ağlar, markaların iletişim kurma biçimini hızla değiştirmektedir. Çevrimiçi imajını ve kimliğini önemseyen kişisel markalar için sosyal ağlar, yeni olanaklar sunmakta ve geliştirmektedir. Bu nedenle, kişisel markalar gelecekteki iletişim stratejileri, geleneksel medya aracılığıyla gönderilen ve çoğu zaman tek yönlü olan bir mesaj yerine, markalama sürecini daha çok iki yönlü bir mesaj olarak düşünmelidir (Argenti, 2013).

Etkileşim sosyal medyada yapılan kişisel markalamanın önemli bir parçasıdır. Araştırmanın amaçları kapsamında Nusr-et resmi Instagram hesabı paylaşımlarındaki etkileşim ve bu etkileşimin boyutları belirlenmiştir. Instagram hesabında yapılan paylaşımların hepsi etkileşim içermektedir. Paylaşımların hepsi tüketiciler tarafından beğenilmiş ve yorumlanmıştır. Paylaşımların genel olarak tüketicide beğenme, yorum yapma ve paylaşma gibi bir tepkiye sebep olduğu 
söylenebilir. Yani Nus-et resmi Instagram hesabının paylaşımları tüketiciyi etkilemekte, tüketicide tepkiye neden olmakta ve bu anlamda amacına ulaşmaktadır.

Nusr-et markasının, kullandığı resmi logosunun yerini 2017 yılından itibaren sosyal ağlarda takipçi sayısının iyice artması ile birlikte tuzlama hareketi aldığı gözlemlenmiştir. Instagram paylaşımlarında marka görseli kullanımına bakıldığında, Nusr-et markasının logosundan daha fazla olarak tuzlama hareketinin öne çıktı̆̆ı tespit edilmiştir. Nusr-et resmi Instagram hesabın yapılan paylaşımların çoğunda ürün, hizmet tanıtımı yer alırken azımsanamayacak sayıda sosyal hayat ve diğer temalı paylaşımları, Nusr-et markasının arkasında yer alan kişilik ve karakteri yansıtmak adına katkıda bulunduğu söylenebilir.

Instagram paylaşımlarında ünlü kullanımı ile takipçi sayısı artış durumu arasında bir ilişki olup olmadığı tespit edebilmek için gerçekleştirilen Ki-Kare Bağımsızlık Testi sonucunda ünlü kullanımı içeren paylaşımlar ile takipçi sayısı artış arasında anlamlı bir ilişki bulunamamıştır $(p>0,05)$. Bunun nedeni ise bazı ünlülerin (David Beckham, Leonardo Dicaprio) diğerlerine göre nispeten daha ilgi çekici ve merak uyandırıcı olmasına bağlanabilir.

Instagram, bir markayı çevrimiçi ortamda tanıtmanın çeşitli yollarını sunması sebebiyle güçlü bir markalama aracıdır. Kişisel markalama için birçok fırsat sunan rekabetçi bir pazarlama aracı olarak düşünülebilir. Tüketicilerle güçlü ilişkiler kurmak ve markasını çevrimiçi kanallar üzerinden oluşturmak için Instagram uygulamasının efektif kullanımı önemlidir. Bu bağlamda Nusr-et resmi Instagram hesabının paylaşımlarında en fazla kullanılan temanın, -iş yerinin, ürün ve hizmetlerin veya marka görselinin birlikte kullanımı- olduğu görülmüştür. Buna paralel olarak en fazla yorum yapılan ve beğeni alan temanın -iş yerinin, ürün ve hizmetlerin veya marka görselinin birlikte kullanımı- olması, sosyal medya pazarlaması çerçevesinde Instagram’ın etkin kullanıldığının ve etkileşim yaratan paylaşımlar yapıldığının göstergesi olduğu söylenebilir.

Kullanıcılar, sosyal medyada bir bağlamda içerik üreticilerine dönüşmüşlerdir. Kullanıcılara kendi web sitelerini ya da profil sayfalarını diğer kullanıcılar ile paylaşabilme olanağı veren uygulamalar olarak tanımlanan sosyal medya siteleri hem kullanıcılar hem de işletmeler için çok önemli bir medya haline gelmiştir (Constantinides ve Fountain, 2008, s. 233). Dolayısıyla Nusr-et resmi Instagram hesabının kişisel markalama unsuru da göz önünde tutulduğunda bu platformu etkin bir biçimde kullandığı görülmüştür. 


\section{KAYNAKÇA}

“BoomSocial.” Erişim Tarihi: 12.04.2018. https://www.boomsocial.com.

"Instagram." About us. Erişim Tarihi: 22.04.2018. http://www.instagram.com/about/us.

Argenti, Paul. 2013. Corporate Communication. New York: McGraw-Hill/Irwin.

Arruda, William, An Introduction to Personal Branding. A Revolution in the Way We Manage Our Careers. www.reachcc.com., $2003 . \quad$ Erişim $\quad$ Tarihi: 19.04.2018. https://www.reachcc.com/reachdotcom.nsf/bfb4f3685c4706d2c1256ad1005d5e63/79325a245696e988c1256de 000431539/Body/M2/intropersonalbrandingv3.pdf!OpenElement.

Bădău, Henry. 2011. Social Media Communication Techniques. Iaşi: Polirom.

Buckmann, Jörg. 2017. Einstellungssache: Personalgewinnung mit Frechmut und Können. Wiesbaden: Springer Gabler.

Carlsson, Lena. 2011. Nya tiders varumärken: varumärkesbyggande kommunikation på den sociala webben. Göteborg: Kreafon.

Chan, Lawranc. 2011. Social Media Marketing for Digital Photographers. NY: John Wiley \& Sons.

Chartered Institute of Public Relations (CIPR). 2012. Share This: The Social Media Handbook For PR Professionals. Chichester: John Wiley \& Sons.

Choi, Namkee ve DiNitto, Dianna. 2013. "The Digital Divide Among Low-Income Homebound Older Adults: Internet Use Patterns, eHealth Literacy, and Attitudes Toward Computer/Internet Use." Journal of Medical Internet Research, 15(5):1-15.

Constantinides, Efthymios ve Fountain, Stegan. 2008. "Web 2.0: Conceptual Foundations And Marketing Issues." Journal of Direct, Data and Digital Marketing Practice, 9: 231-244.

Dunne, Aine., Lawlor, Margaret ve Rowley, Jennifer. 2010. Young People's Use Of Online Social Networking Sites A Uses And Gratifications Perspective. Journal of Research in Interactive Marketing, 4(1): 46-58.

Gökçe, Orhan. 2006. İçerik Analizi Kuramsal ve Pratik Bilgiler. Ankara: Siyasal Kitabevi.

Gubbi, Jayavardhana., Buyya, Rajkumar., Marusic, Slaven ve Palaniswami, Marimuthu. 2013. "Internet Of Things: A Vision, Architectural Elements, And Future Directions.” Future Generation Computer Systems, 29(7): 16451660.

Kaplan, Andreas ve Haenlein, Michael. 2010. "Users Of The World, Unite! The Challenges And Opportunities Of Social Media." Business Horizons, 53(1): 59-68.

Kaputa, Catherine. "The Art Of Branding." SelfBrand. 2003. Erişim Tarihi: 17.04.2018. www.selfbrand.com/ArtBranding Yourself.html.

Khedher, Manel. 2014. "Personal Branding Phenomenon." International Journal of Information, Business and Management, 6(2): 29-36.

Kim, Myung-Ja., Chung, Namho ve Lee, Choong-Ki. 2011. "The Effect Of Perceived Trust On Electronic Commerce: Shopping Online For Tourism Products And Services In South Korea.” Tourism Management, 32(2): 256-265.

Lair, Daniel., Sullivan, Katie ve Cheney, George. 2005. "Marketization And The Recasting Of The Professional Self: The Rhetoric And Ethics Of Personal Branding.” Management Communication Quarterly, 18(3): 307-343.

Leech, Nancy., Barret, Karen ve Morgan, George. 2008. SPSS For Intermediate Statistics, New York: Taylor \& Francis Group.

Moreau, Elise. "What Is Instagram. Web Trends.” 2015. Erişim Tarihi: 22.04.2018. http://webtrends.about.com/od/prof4/a/What-Is-Instagram-Wiki.htm.

Ollington, Nickolas., Gibb, Jenny ve Harcourt, Mark. 2013. "Online Social Networks: An Emergent Recruiter Tool For Attracting And Screening." Personel Review, 42(3): 248-265.

Peters, Tom. 1997. “The Brand Called You.” Fast Company, 10(10): 83-87.

Rouse, Margaret. "Social Media Marketing (SMM)." TechTarget. 2011. Erişim Tarihi: 21.04.2018. http://whatis.techtarget.com/definition/social-media-marketing-SMM.

Safko, Lon. 2012. The Social Media Bible: Tactics, Tools, And Strategies For Business Success. Hoboken: John Wiley $\&$ Sons.

Salvador, Eveleyn. 2011. Step-by-Step Cover Letters. USA: JIST Works.

Schwabel, Dan. 2009. Me 2.0: A Powerful Way to Achieve Brand Success. New York: Kaplan Publishers.

Shepherd, Ifan. 2005. "From Cattle and Coke to Charlie: Meeting the Challenge of Self Marketing and Personal Branding." Journal of Marketing Management, 21(5-6): 589-590.

Vitberg, Alan. 2010. "Developing Your Personal Brand Equity.” Journal of Accountancy, 21(1): 56-76. 
Kaya, F., Uğurhan, Y., Z., C., Bayçu Uzoğlu, S. / Journal of Yasar University, 2019, 14/54, 196-207

Voorveld, Hilde. Van Noort, Guda ve Duijn, Meryl. 2013. "Building Brands With Interactivity: The Role Of Prior Brand Usage In The Relation Between Perceived Website Interactivity And Brand Responses.” Journal of Brand Management, 20(7): 608-622.

Wimmer, Roger ve Dominick, Joseph. 2000. Mass Media Research: An Introduction. CA: Wadsworth. Yıldırım, Ali ve Şimşek, Hasan. 2016. Nitel Araştırma Yöntemleri. İstanbul: Seçkin Yayıncılık. 
Kaya, F., Uğurhan, Y., Z., C., Bayçu Uzoğlu, S. / Journal of Yasar University, 2019, 14/54, 196-207

\section{Ek 1. Operasyonel Tanımlar}

Paylaşım Türü: Nusr-et resmi Instagram hesabında yapılan paylaşımların video ve fotoğraf türüne göre dağılması.

- Video; hem görüntü hem ses içeren daha önce kaydedilmiş medyadır.

- Fotoğraf; çeşitli araç ve malzeme kullanarak görüntüyü bir yüzey üzerine sabitleme olarak tanımlanmaktadır.

Ürün veya Hizmet: Nusr-et markasının ürün ve hizmetlerinin paylaşımlarda yer alması.

Marka Görseli: Nusr-et markasının öne çıkardığı simgesinin logo ve tuzlama hareketi olarak ikiye ayrılması

- Logo; Nusr-et markasının, isminin harf ve resimsel ögeler kullanılarak sembolleştirilmesi

- Tuzlama Hareketi; Nusret Gökçe'nin kendine özgü hareketi ile et ürünlerine tuz atması

Paylaşım Teması: Instagram'da bulunan her bir görsel paylaşıma (video, fotoğraf) oluşturulan kategoriler içerisinden bir tanesi ile eşleştirilmesi. Paylaşım kategorileri; sosyal hayat, ünlü kullanımı, ürün ve hizmetler, iş yeri ürün ve hizmetlerin ya da marka görselinin beraber kullanımı, başka kişi veya kurumların tanıtımı, diğer paylaşımlarıdır.

- Sosyal Hayat; Nusret Gökçe’in iş hayatı dışarısında yaptığı spor veya etkinlik, açılış gibi paylaşımlardır.

- Ünlü Kullanımı; Nusr-et Instagram hesabında yapılan paylaşımlarda ünlü kişilerin yer alması.

- Ürün Hizmet; Nusr-et markasının ürünlerinin içeriklerde yer alması.

- İş Yeri, Ürün ve Hizmetlerinin ya da Marka Görselinin Beraber Kullanılması; Nusr-et işletmelerinin, ürünleriyle ve marka görseli olarak logo veya tuzlama hareketi ile birlikte kullanımı.

- Başka Kişi veya Kurumların Tanıtımı; Nusr-et Instagram hesabında yapılan paylaşımlarda kendisi haricinde bir kişi veya kuruma dair tanıtım içeriğinin bulunması.

- Diğer Paylaşımlar; Diğer tanımlanmış paylaşım temalarına dâhil olmayan Instagram içeriklerinin yer alması durumda kullanılan tema.

Ürün ya da Hizmet Tanıtımının Olup Olmaması: Instagram paylaşımında ürün veya hizmet tanıtımının belirlenmesi.

- Tanıtım, bir markaya ait ürün ve hizmetlerini, onların özelliklerini, üretim biçimini, teknolojisini, yüklediği veya yarattı̆̆ı duygusal bağlar vasıtasıyla kuramsal kimliği ile geniş kitlelerine, benimsemesini, istemesini sağlayacak şekilde yapılan çalışmalardır.

Doğrudan Ünlü Kullanımı: Paylaşımda yer alan ünlünün fiziki olarak iş yerinde veya Nusret Gökçe'nin yanında bulunmasi.

Dolaylı Ünlü Kullanımı: Paylaşımda yer alan ünlünün, fiziki olarak Nusret Gökçe ile beraber olmayıp içerikte etiketleme, tuzlama hareketi veya Nusret Gökçe’ye atıf vasıtasıyla yer alması. 